\title{
Knowledge Training and Transferring in Hoang Duong Joint Stock Company - Vietnam
}

\author{
Minh Nguyen Van, Nam Tran Hoai \\ Department of Economic Information System and Electronic Commerce, Thuongmai University, Hanoi, Vietnam
}

Email address:

minhdhtm@gmail.com (N. V. Minh),namth@tmu.edu.vn (T. H. Nam)

To cite this article:

Minh Nguyen Van, Nam Tran Hoai. Knowledge Training and Transferring in Hoang Duong Joint Stock Company - Vietnam. Science Journal of Business and Management. Vol. 5, No. 4, 2017, pp. 149-157. doi: 10.11648/j.sjbm.20170504.13

Received: April 18, 2017; Accepted: April 26, 2017; Published: July 5, 2017

\begin{abstract}
This study analyses the training and transferring of knowledge in Hoang Duong Wool Joint Stock Company in Vietnam as a case study. This case study is described and analyzed through logic of a conceptual framework of knowledge transferring from literature review. Questionnaire survey and in-depth interview methods are used to collect data and information. As a result, leaders' awareness and commitment in training and transferring of knowledge are rather high. Besides, the training design is usually taken place according to company's plan. Some of training contents are successfully applied. However, quantity and quality of trained knowledge application has not been high and effective. Finally, this study gives some recommendations to enhance company's training and transferring.
\end{abstract}

Keywords: Training, Knowledge Transferring, Application

\section{Introduction}

\subsection{Vietnam Textile and Garment Industry}

\subsubsection{Vietnam's Position in Global Chain Value}

Over the last years, Vietnam textile and garment industry (VTG) has been a main export industry of Vietnam. The strengths of VTG are (1) Equipment is innovated and modernized up to $90 \%$; (2) Setting closed relationship up with domestic and global partners based on advantages of the cheap and good skill workforces and (3) Political stability and social security, positively participating in economic integration in the region and the world... However, VTG still has many limitations and challenges, such as (1) Most of garment for export is outsourcing (cutting, sewing, assembling), textile and supporting industry are low-powered, lack of quality materials for export, causing low value added; (2) Most of Vietnam textile/garment companies are SME (small and medium enterprises), so their investment in terms of capital is low, technology/equipment innovating ability is limited, adapting ability due to the market changes is weak; (3) Technical and management skills are poor, not professional trained yet, low productivity; marketing capabilities are limited, not had long-term strategy and not much brands "made in Vietnam" yet. Global value chain of exporting textile industry has 05 basic steps, includes Design, Materials Production, Production, Exports, and Distribution. Vietnam is engaged mainly in the outsourcing production at the bottom of the value chain.

\subsubsection{Labors}

Wage of labor in Vietnam textile and garment industry is around 0,52USD / hour in 2010. It is one of the lowest over the world, just above the Cambodian by $0,24 \mathrm{USD} /$ hour and Bangladesh by $0,21 \mathrm{USD} /$ hour. Cheap labor in garment sector is an advantage but as well as challenge for selecting of skilled workers and keeping them on the long-term with the company.

\subsubsection{Materials}

More than $80 \%$ of materials are still imported from countries such as China, Taiwan, Korea, Thailand [17]. General supporting industry and textile supporting industry have developed slowly. After participating the Trans-Pacific Partnership (TPP), Vietnam textile and garment industry will have more opportunities to develop. The technology transfer is necessary for many Vietnam enterprises at that time. However, the Vietnam textile and garment enterprise is not qualified to receive the technology and techniques because 
they are lack of a team of skilled engineers and workers to operate and manage the machinery, equipment. It is a reason for a training strategy for human resources in this industry.

\subsection{Introduction of Hoang Duong Wool Joint Stock Company}

Hoang Duong is a company in the Vietnam textile and garment industry, which specializes in products made from wool, yarn. Being in the supply chain of Vietnam textile and garment industry, Hoang Duong have also faced with the same difficulties, even more, because the wool, yarn are the narrow fields which have not been much attention from Vietnam Textile Association. Hoang Duong is also the firm that uses many labors; as a result it has been heavily influenced by the objective scenes, such as: seasonal workers, market fluctuations. For example, in 2014, the company's revenue declined of $10 \%$ in comparison with 2013 , besides the objective reason was order reducing, the subjective reason was employee jumping. In addition, sometimes, the skills of current employees do not meet the high requirement order, leading to not reach the great value orders. Although the company has also been interested in training for the managers, employees and workers, the transferring of this trained knowledge is still a long process that needs further investment.

\subsection{Objectives of Study}

To research the training and transferring of knowledge of Hoang Duong wool Joint Stock Company through logic of conceptual framework from literature review, which shows relationships between trainee characteristics, trainee design, working environment and learning knowledge/skills; then training transfer to workplaces. Namely, the case study will show contents of training course, training methods, trainers, trainees, results of training and transferring in the company.

\section{Literature Review}

"Transfer of training" as transfer of acquired knowledge and skills to workplace has been argued within more general frameworks for training evaluation. Starting from four level model identifying reaction - learning - behavior (= transfer of training) - result [9], some other models have been proposed, for instance, one adding return on investment (ROI) as the fifth level [11] and one including characteristics of trainees and organizations that are factors beyond learning events [8]. Transfer of training has been argued as one of the main topics in order to overcome difficulties in reflection and maintenance of learning contents into workplace behavior [13]. Empirical studies have been accumulated [4], [6], [7], [10], [12], [14], [15] while some review articles including meta-analyses been published [1], [2], [3], [5].

Since the end of 1980s a lot of studies have attempted to refine the Baldwin \& Ford's (1988) basic model that describes the effects of trainee characteristics, training design and work environment on training transfer as well as knowledge/skills acquirement. The present study extends the basic model into transfer at team and organization level and incorporates other factors such as knowledge/skill characteristics that affect transfer process. The scope of prior "training transfer to workplace" studies was limited to the analysis on individual behavioral change and not targeted to transfer to the broader ranges like team and organization level. They were not studied in comprehensive and systematic ways, although there have been cases analyzing the characteristics of knowledge/skills acquired [3]. This study will use the extending framework as a logic map to research training and transferring of knowledge on a case study.

\section{Research Methods}

\subsection{Questionnaire Survey}

Survey by questionnaire is conducted based on common questionnaires designed from the project and translated into the native languages of the countries involved in the research.

02 forms of questionnaires were designed for Hoang Duong: Form 1 for managers, Form 2 for trainees (both are in Hoang Duong company and trained by Vietnam Japan Human Resources Cooperation Center - VJCC).

With Form 1, a survey was conducted in conjunction with in-depth interview $01 \mathrm{CEO}$ to collect more detail information. Main contents in questionnaire:

(a) Value chain and network

(b) Competitiveness and capabilities

(c) Human resource development/management

With Form 2, the questionnaires were sent to 04 staffs (Head of departments of Hoang Duong), to let them read and choose their appropriate answers, then they sent back to us by post office. Main contents in questionnaire are as follows:

(1) Personal information

(2) Trainee characteristics

(3) Training design

(4) Working environment

(5) Organizational learning

As mentioned, questionnaire survey was used in this research. Although the sample was very limited, just 4 trainees from VJCC, information captured by those respondents are really important and useful for us to understand the company's process of training transfer. 5 point Likert scale was used in this questionnaire ranging from $1=$ strongly disagree to $5=$ strongly agree. The items to measure all variables were adopted from previous researchers. Then all information was analyzed using SPSS to take mean value and standard deviation.

\subsection{In-depth Interviews}

The depth interview is combined with the survey by using the Form 1 for managers. Authors went directly to the company on 29th January 2016, which locates in Hung Yen province around $30 \mathrm{~km}$ far from Hanoi. At that time, the CEO gave presentation introducing about his company, and issues regarding learning, transfer, and application of knowledge 
from Vietnam - Japan Human Resources Cooperation Center (VJCC) to BMC. Questions were also raised during the presentation. After that, the research team had a visit around the company and manufacturing area. During and after this visit, authors also asked questions in terms of production process, training transfer to production, how the firm overcomes differences between knowledge that they learned and the reality. Authors have also got a field trip to the company to look around and take some photos. Moreover, information about the company was collected through its website and documents which were finally analyzed by descriptive analysis.

\subsection{Secondary Data Collection}

Secondary data was collected by receiving the information (hard copies and soft copies) from the Hoang Duong JSC., about the company profile, the improving activities in production process (training, technology transfer, such as 5S, Kaizen ...) through images, documents, reports and so on.

\section{Analysis Results}

\subsection{General Information of Hoang Duong JSC}

\subsubsection{Hoang Duong's Profile}

Name: Hoang Duong Service and Commerce Joint Stock Company

Brand name: Canifa (in other company with a different CEO but same Chairman)

Canifa's products which are supplied by Hoang Duong:

For winter: key products such as wool/yarn products and warm cloth coats.

For summer: spandex and cool kaki products.

For children: wool, yarn, cotton for winter and summer.

History:

(i) 1977: Established from household business,

(ii) 2011: created a new brand named Canifa - a famous and reputed brand on products from wool, yarn of Vietnam

(iii) 4/2012: Hoang Duong transformed their legal status to Joint Stock Company.

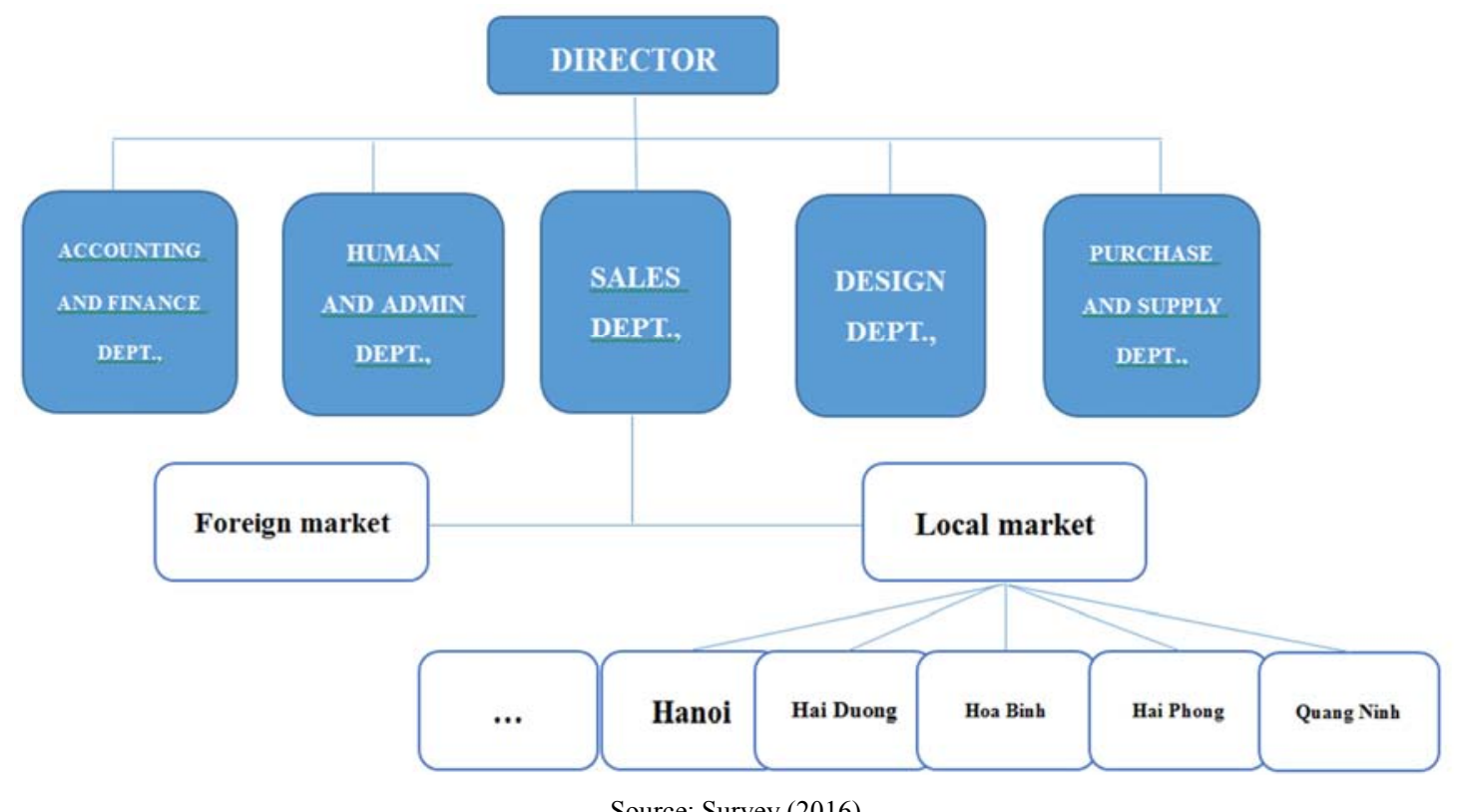

Figure 1. Organizational chart.

Hoang Duong JSC., is a local private enterprise (100\% local private ownership, without state/foreign ownership)

Senior Management Board has 03 people, including 01 president, 01 Vice President and 01 CEO. CEO - interviewee
- is a 35 years-old male with Bachelor degree and 13 years experience.

Some business indexes:

Table 1. Business statistics of Hoang Duong JSC.

\begin{tabular}{llll}
\hline Index/Year & $\mathbf{2 0 1 5}$ & $\mathbf{2 0 1 4}$ & $\mathbf{2 0 1 3}$ \\
\hline Total employees (person) & 200 & 174 & 160 \\
Turnover (billion VND) & 40 & 32 & 143 \\
Profit (percent/turnover) & $\sim 6 \%$ & $\sim 6 \%$ & 36 \\
\hline
\end{tabular}

In 2014 , revenues declined more than $10 \%$ that is explained by reducing in market demand and fluctuating of manpower in company. Lots of employees quitted because of reducing orders.

\subsubsection{Value Chain and Corporate Networks}

Main products: all kinds of shirts, hats, towels from wool / 
yarn, accounting for $100 \%$ of the total revenue. The flow of products going through the 3 main stages:

(1) Input, including the balance of materials, choice of supplier;

(2) Production, with 6 stages as Winding yarn, Color subdivision, Textiles (pieces/parts), Assemble (linking), Washing/Drying/Ironing, Packing;
(3) Supply to customer and service.

In each stage, quality control is performed to remove the low quality parts. It takes the 5 days for a completed product. At present, Hoang Duong produce according to the different clusters (textile cluster, assembly cluster, washing cluster...) instead of complete line product from beginning to ending because of small volume of orders. Figure 2 can show this process:

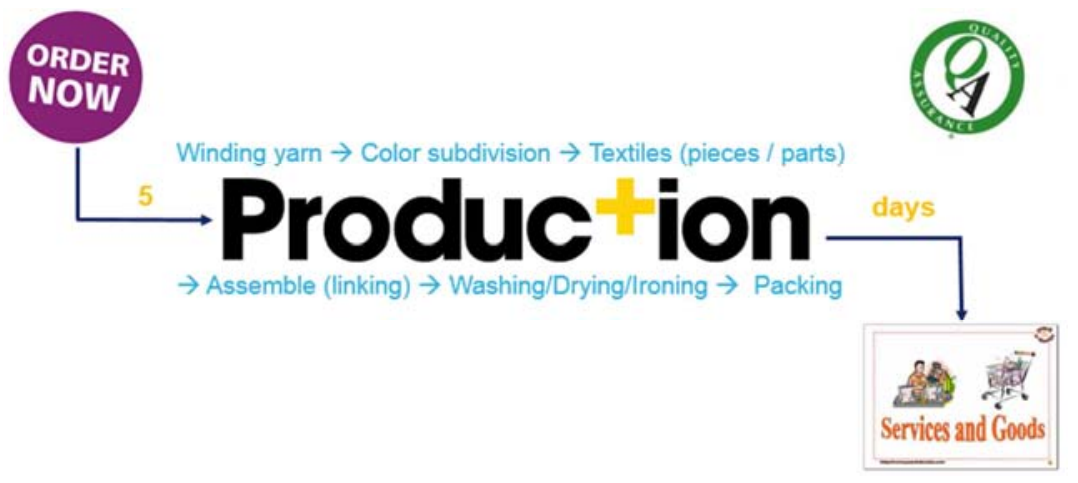

Source: Survey (2016)

Figure 2. The flow of production.

Major customers by country are Vietnam by $80 \%$ (for Canifa company), followed by South Korea and Japan which is about $10 \%$ per country. Major customers by ownership are domestic customers by $80 \%$ (for Canifa private company) and the rest are private customers from Japan, Korea.

Company indirectly exports its main products through a few small commercial companies. The proportion of export revenue accounted for $20 \%$ of total turnover.

Major suppliers of key raw materials (provided $80 \%$ of the materials, including cotton, yarn, needle, thread, dye ...) for Hoang Duong are Chinese suppliers by $95 \%$; others from Indonesia, Philippines by 3-4\%; while Vietnam suppliers mainly supply cartons, plastic bags, labels by $1-2 \%$.

The association that Hoang Duong is participating:

(1) Vinatex_Vietnam Textile Association: mainly enterprises are textile products, therefore wool products (as Hoang Duong company) is not received much attention. Company pays a small annual fee to participate, but so far it has not had any benefit from this Association (partners, customers...).

(2) Wallmart, AWI: several times when joining to a project, Hoang Duong had products while partners had customers/materials.

Notes: AWI is the Germany shepherd association that connects between producers of fleece products and manufacturers.

\subsubsection{Competitiveness and Capabilities of the Company}

Overall competitiveness of is average among domestic competitors. In the North of Vietnam, Canifa's competitiveness (products provided by Hoang Duong) is quite good in the top 5 .

Business-external problems of Hoang Duong are basically not difficult, only a small competitiveness from a few foreign rivals. In fact, this small competition has reason from Hoang
Duong's scale and production capacity that are still small, has not enough competitive intense with them.

Business-internal challenges: partly due to lack of machinery and equipment, but most are in developing skills for labor and product quality management.

(a) Challenges in developing skills for labor: Hoang Duong usually has preferred the staff/workers who work for a long time since established when they choose people to send for training. Beside the advantages, the biggest disadvantage of this regulation is making these staff/workers to be dependent and slowly improved. The labor's skills are not high, not satisfy of foreign customers' demand, leading to loss many orders or not enough production capacity after designing.

(b) Challenges in Product quality management: Wool/Yarn products are handmade products at mostly all of stages, so it depends on labor (labor's skills/experience/health/mood...) with high risky at all stages. Meanwhile, the company has not been standardized quality management yet, leading to the cost and time for resolving the problem quite high. Although the direct workers must also take responsibility for product quality, obviously it wastes for all parties.

New investments recently: in late 2015, the company purchased a Japanese automatic textile chain named Shieki Shima for production of summer wool products, being worth of 10 billion to prepare for the spring and summer of 2016.

New innovation recently: around May 2015, the company has established an office in Hai Phong province (far from Hanoi capital about $90 \mathrm{~km}$ and Hung Yen province about $70 \mathrm{~km})$. This office has responsibility for recruiting the workers who are unemployed from other dissolved foreign companies in Hai Phong province. This innovation 
(organizational innovation) has brought many positive signs for finding the high qualified labors.

Quality management system certifications: Hoang Duong used to take procedures for ISO 9000 but not completed. On the one hand, its total cost is rather high. On the other hand, their customer has no requirement of those certifications. As a result, Hoang Duong has not had any certificates until now.

Internal R \& D: Hoang Duong has R \& D department, but its role and function are not clear because of their main job is outsourcing by customer's orders, R\&D is not an urgent demand. Sometimes, they also try a number of new products (such as blankets, sheets, pillows ...) but have no enough capacity to produce.

Technical assistance (TA) / business development service (BDS): from both of domestic and foreign partners.

(a) From foreign sources: mainly from their purchasing of machinery. Machinery producers will send their staff/technicians to Hoang Duong factory for training and coaching, 4-5 times for new equipment, then 1-2 times annually. Other sources have not found.

(b) From domestic sources: mainly from training courses of VJCC, VCCI or consulting experts for training on accounting, techniques....

VJCC's training is considered more effective but rather different in applying in Hoang Duong company (Vietnamese spirit, culture... are different with Japanese's). The most beneficial course is the "Key Course_Japan Production Management Method" (teacher Se-mi-ru). Hoang Duong said that if this course is trained directly at their factory, it will bring more effectiveness (teacher trains, indicate, rearrange... directly at factory).

\subsubsection{Management Resource Development/Management}

Evaluation on employees' knowledge/skill level: still need more training and development, but compared with other competitors in Vietnam, Hoang Duong's labor capacity is the best and became the recruiting goal of other competitors if they want to change their job.

Training (off-JT) implementation: mainly from VJCC/VCCI, and VJCC is more benefits. In addition, Hoang
Duong also received some training from industry associations, some private organizations, government agencies, and foreign organizations.

Internal training is also taken place in company frequently:

(a) A few years ago, CEO trained other people after his training courses (1 time/week during 4-5 months; then trainees apply)

(b) From 2015: several times per year because Hoang Duong want to focus on production and has no trainers.

(c) Contents of training courses are management, customer relation, sale, leadership, team working, and technical skills. External trainings usually follow module such as 5S, KPI, BSC... (VJCC). Internal trainings are often focused on initial training, soft skill training, and so on (senior train junior).

(d) Trainees: off-JT for people who are from vice-head of departments up, and on-JT for workers by more experienced workers/staff.

Degree of satisfaction on training: the most beneficial training course is Japan Production Management Method course, while others from VCCI are less.

Employees' benefit from training: improve their skills to help them more confident and have chance to get promoted. A few years ago, Hoang Duong used to add the bonus for those trained employees who applied well in their job but not now because it is not suitable for Hoang Duong's finance.

Average years of service by employees: over 10 years $(56 \%$ of employees).

Turnover ratio: almost no, only because of their personal reasons or from their trial work.

Internal promotion or recruitment from outside: applying the regulation of priority for long time working staff but still choose from outside for job's need.

\subsection{The Training and Transferring of Knowledge in Hoang Duong JSC}

The training and transferring of knowledge in the Hoang Duong JSC have remained regularly over the years. Some data in our survey are as follows.

Table 2. Status of training and transferring of knowledge in Hoang Duong JSC.

\begin{tabular}{|c|c|c|c|}
\hline No. & Contents & Training & Transferring \\
\hline 1. & Trainers & $\begin{array}{l}\text { VJCC, VCCI: training courses } \\
\text { Private companies: exchange knowledge, discussion } \\
\text { Foreign companies: from the equipment purchasing contracts }\end{array}$ & $\begin{array}{l}\text { CEO } \\
\text { Managers } \\
\text { Training staff } \\
\text { Human resource staff }\end{array}$ \\
\hline 2. & Trainees & $\begin{array}{l}\text { CEO } \\
\text { Managers } \\
\text { From Vice-Head of Department up } \\
\text { Professional staff: accountants, human staff, technicians }\end{array}$ & $\begin{array}{l}\text { Managers } \\
\text { Staff } \\
\text { Workers }\end{array}$ \\
\hline 3. & Methods & $\begin{array}{l}\text { Learning from outside } \\
\text { Learning from experts } \\
\text { Self-learning }\end{array}$ & $\begin{array}{l}\text { Experts (from purchasing contracts) } \\
\text { Self-training (by managers, team leaders) }\end{array}$ \\
\hline 4. & Contents & $\begin{array}{l}\text { Techniques } \\
\text { Accounting } \\
\text { Production management: 5S, Kaizen... }\end{array}$ & $\begin{array}{l}\text { Skills in production } \\
\text { Production management: } 5 \mathrm{~S} \text {, Kaizen... }\end{array}$ \\
\hline 5 . & Time & Annual plan & Depending on job's demand and have new employees \\
\hline 6. & Results & Annual report of number of trainees & Not had visible results yet (i.e. $5 \mathrm{~S}$ application) \\
\hline
\end{tabular}

Source: Survey (2016) 
Some images of 5S application in Hoang Duong JSC can show their first results but not really effectiveness.

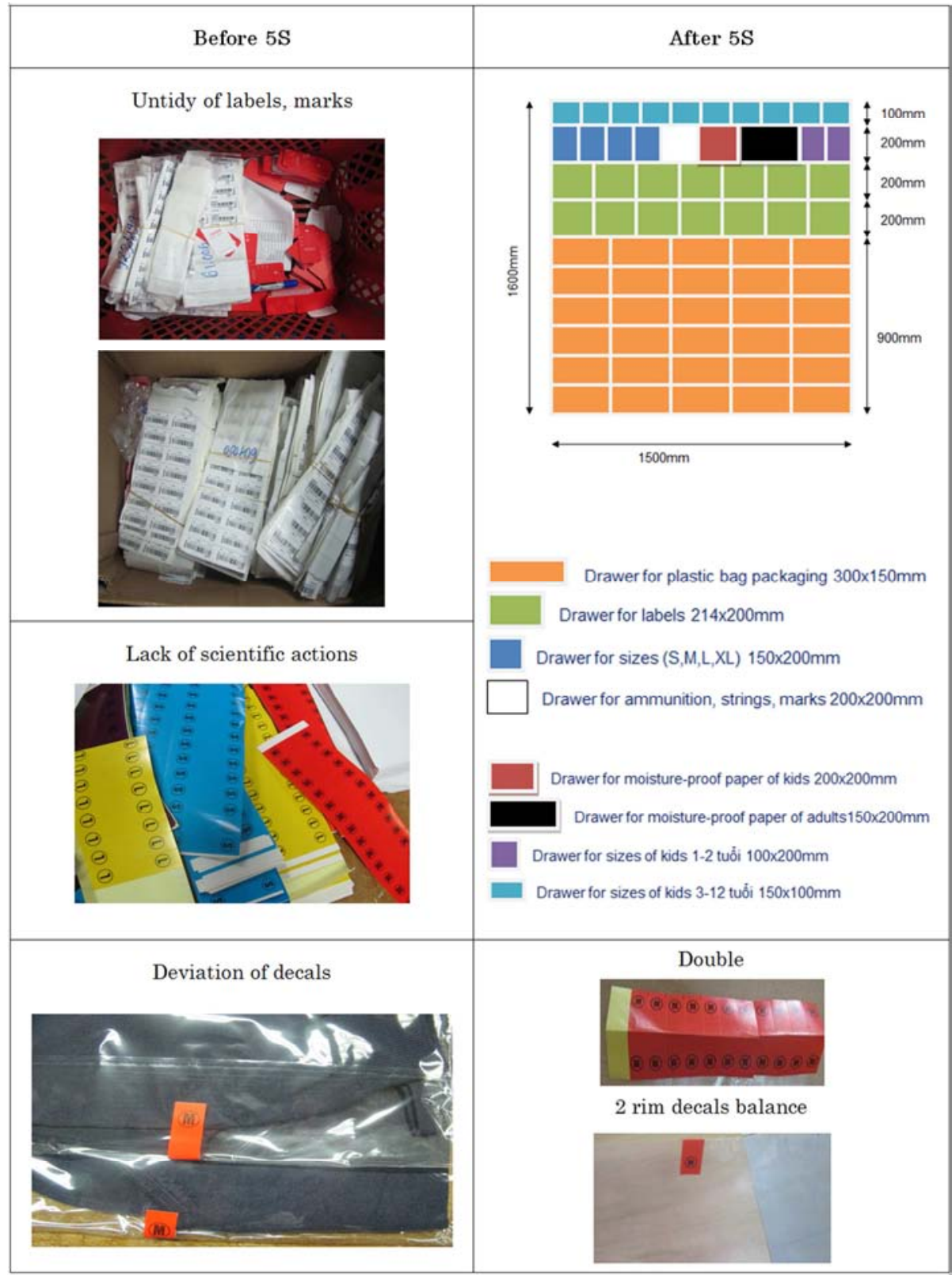

Source: Hoang Duong profile (2016)

Figure 3. Images of before-after $5 S$ application in Hoang Duong JSC.

Table 3. Detail contents of Form 2 questionnaire.

\begin{tabular}{llllll}
\hline No. & Contents & Point & No. & Contents & Point \\
\hline 1 & Trained by VJCC & yes & 5 & Work environment & 3.44 \\
2 & Personal information & 04 persons & 5.1 & Support & 3.05 \\
& Age/Education & 36.3 / Bachelor & 5.2 & Opportunities to use & 3.67 \\
& Position & Head of Dept. up & 5.3 & Knowledge and skills acquired & 3.31 \\
3 & Trainee characteristics & 3.02 & 5.4 & Training transfer to workplaces & 3.08 \\
3.1 & Learner readiness & 3.17 & 5.5 & Motivation to learn & 3.92 \\
3.2 & Performance self-efficacy & 2.88 & 5.6 & Motivation to transfer & 3.58 \\
4 & Training design & 3.13 & 6 & Organizational learning & 3.78 \\
4.1 & Perceived content validity & 2.94 & 6.1 & Managerial commitment (MC) & 4.10 \\
4.2 & Transfer design & 3.31 & 6.2 & Systems perspective (SP) & 3.75 \\
& & & 6.3 & Openness and experimentation (EX) & 3.94 \\
& & & 6.4 & Knowledge transfer and integration (TR) & 3.56 \\
\hline
\end{tabular}

Source: Survey (2016) 
Results in training and transferring of knowledge in Hoang Duong Company are as follows:

(a) Content 1: All respondents are trained by VJCC

(b) Content 2: All respondents are from Company's Deputy / Head up

(c) Content 3: Trainee characteristics reached 3.02 points, is the low score, the lowest of all the asked contents, showing Trainee characteristics do not meet the requirements for training and transferring of knowledge in Hoang Duong Company. This content consists of 02 questions:

(1) 3.17 points for the question of Learner readiness, was the average score. This proves that the learner is neither passive nor active in their learning, just because of the requirements from company.

(2) 2.88 points for the question of Performance self-efficacy, was the low score, the lowest of all the questions. This proves that the learner is not confident about their job performance. Maybe their knowledge and skills cannot meet better requirement of the job, making their work not effective.

(d) Contents 4: Training design reached 3.13 points, as well as the low score, demonstrating Training design has not achieved the requirements in training and transferring of knowledge to learners. This content consists of 02 questions:

(1) 2.94 points for the question of Perceived content validity, as the average score. This shows the value of training content is not appreciated, leading to low effectiveness of the job training. These trained people, or apply less, or are not effective application.

(2) 3:31 points for the questions of Transfer design, was the rather good score. Although the training content is not well realized, the transferring of knowledge is done quite well. The trainer uses many application examples of the work to help the trainee feels more confident when accepting new knowledge and applying them on their job.

(e) Content 5: Working environment reached 3.44 points, is the rather good scores, demonstrates Working environment at the company Hoang Duong relatively meet the requirements of the training and knowledge transfer. This content consists of 06 questions:

(1) 3.05 points for the questions of Support, is the average score, but the lowest in this $5^{\text {th }}$ content. Trainee's co-workers and direct manager are not much interested in what they learn, whether they can apply on their job or not, not require or encourage the application.

(2) 3.67 points for the questions of Opportunities to use, is also quite a high score. This shows that the trainee always has the opportunities and the resources to use their trained knowledge/skill in their work.

(3) 3:31 points for the questions of Knowledge and skills acquired, is a rather good score. Their trained knowledge / skills are quite appropriate, enhancing their capacity after training and get promoted in jobs. However, the remembering of most trained knowledge / skills is relatively hard, so they should have the instruction documents or apply during / after training or combine with job instruction, to help the trainee remember longer.

(4) 3:08 points for the questions of Training transfer to workplace, is the same as the score of question Support. Although knowledge is believed to be in conformity, is absorbed quite well but most of trainees have not applied / transferred a lot in their work. This causes from a lack of support from their colleagues and direct managers.

(5) 3.92 points for the questions of learning Motivation to learn, is the high point, the highest in this $5^{\text {th }}$ content. Learner believed that learning is a good opportunity to enhance their work and they try to learn as much as possible from the training courses. However, they do not think they are motivated by anyone or anything to participate in these courses but just motivation from themselves and their job only.

(6) 3:58 points for the questions of Motivation to transfer, is a rather good score, achieved at the middle level of this $5^{\text {th }}$ contents. This is similar to Motivation to learn, the trainee feels excited when trying to use the trained knowledge / skills on their job, and this is the main motivation for the transferring of trained knowledge. However, the opportunity and promotion of the transferring are not achieved at high level, so the point of Motivation to transfer has been at a rather point.

(f) Contents 6: Organizational learning, achieved 3.78 points, is the high score, and the highest in all questions, proving the Organizational learning in Hoang Duong company has met the requirements of training and transferring of knowledge in company. This content consists of 04 questions:

(1) 4:10 points for the question of Managerial Commitment $(M C)$, is the high score, the highest in all of this $6^{\text {th }}$ content. It is evident that the company attaches great importance to the training and development of their staff / workers, expressed by their annual outside/internal training plan. Manager considers the training is an investment rather than an expense, they often engage their employees into their making important decisions, consider their employees' learning ability as a major factor. Besides, training is regarded as a reward and the signal for assigning more responsibility and authority.

(2) 3.75 points for the question of Systems perspective $(S P)$, is as well as the high point. This shows that all employees can understand the training objectives, understand their contribution to the training and cooperate with each other to reach a real effectiveness.

(3) 3.94 points for the question of Openness and 
experimentation (EX), is the high point, just behind the MC question. In the inner meaning of this question, the content of company's culture reached the maximum points ( 4.75 / 5 score $)$, demonstrating their openness in learning and development has become a part of corporate culture. Besides, the consideration and attention to the new elements are also their focused items. They are always ready for experimentation and innovation as an improving way of work process, and also willing to learn from other companies to increase their work efficiency.

(4) 3:56 points for the question of Knowledge transfer and integration (TR), even though is the lowest score in this $6^{\text {th }}$ content, still is a rather score. In Hoang Duong, employees always have the opportunity to talk about new ideas, new programs, and useful activities for companies by the regularly team work. Here, the error and the failure have always been discussed and analyzed at all levels to get the better solutions.

Some achievements of the training and transferring of knowledge in Hoang Duong

(1) Awareness and high commitment of leaders

(2) Some of the content has been applied in the work

(3) Internal training and transferring is done regularly

(4) Effects of training expressed in a part

Some limitations of the training and transferring of knowledge in Hoang Duong

(1) Contents of the courses have not acquired fully

(2) The rate of learning-acquiring-applying-transferring in the team descending.

(3) Effective / successful application of training is still low Causes of limitations

(1) Learning spirit is not highest, leading to a not fully acquiring.

(2) Contents of training are not closed to reality and cannot be applied immediately on the job.

\section{Conclusions and Implications}

This paper analyzes the training and transferring of knowledge in Hoang Duong - a company of Vietnam specializes in manufacturing fashion products from wool, yarn. Using survey by questionnaire and in-depth interviews, the study shows that the awareness and commitment of the company's leaders in training and transferring of knowledge is quite high. Besides, the training has been carried out regularly, according to their plan. Some training contents have been applied successfully in the job and whole company. However the quantity and quality of trained knowledge/skills application are low and not high efficiency.

In order to improve the limitations of the training and transferring of knowledge in Hoang Duong Company, some recommendations are suggested as follows:

First, build up the mechanism of training and knowledge transferring: quantity of learners, contents, time, reward and punish for bad/good learning/applying.
Second, determine the detailed content of training courses from VJCC, VCCI... to focus on practical necessary training for company.

Third, invite the most skilled engineers to train directly in companies.

\section{References}

[1] Baldwin, T. T. \& Ford, J. K. (1988), 'Transfer of training: a review and directions for future research', Personnel Psychology, 41: 63-105.

[2] Baldwin, T. T., Ford, J. K. \& Blume, B. D. (2009), 'Transfer of training 1988-2008: an updated review and agenda for future research', in Hodgkinson, G. P. \& Ford, J. K. (eds.), International Review of Industrial and Organizational Psychology, Volume 24 (Chapter 2), John Wiley \& Sons, Chichester, UK.

[3] Blume, B. D., Ford, J. K., Baldwin, T. T. \& Huang, J. L. (2010), 'Transfer of training: a meta-analytic review', Journal of Management, 36: 1065-1105.

[4] Burke, L. A. \& Baldwin, T. T. (1999), 'Workforce training transfer: a study of the effect of relapse prevention training and transfer climate', Human Resource Management, 38(3): 227-242.

[5] Burke, L. A. \& Hutching, H. M. (2007), 'Training transfer: an integrative literature review', Human Resource Development Review, 6: 263-296.

[6] Facteau, J. D., Dobbins, G. H., Russell, J. E. A., Ladd, R. T. \& Kudisch, J. D. (1995), 'The influence of general perception of the training environment on pertaining motivation and perceived training transfer', Journal of Management, 21: 1-25.

[7] Holladay, C. L. \& Quinones, M. A. (2003), 'Practice variability and transfer of training: the role of self-efficacy generality', Journal of Applied Psychology, 88(6): 1094-1103.

[8] Holton, E. F. (1996), 'The flawed four-level evaluation model', Human Resource Development Quarterly, 7(1): 5-21.

[9] Kirkpatrick, D. L. (1959), 'Techniques for evaluating training programs', Journal of the American Society of Training Directors, 13(11): 3-9.

[10] Lysø, I. H., Mjøen K. \& Levin, M. (2011), 'Using collaborative action learning projects to increase the impact of management development', International Journal of Training and Development, 15(3): 210-.224

[11] Phillips, J. J. (1996), 'Measuring ROI: the fifth level of evaluation', Technical \& Skills Training, April: 11-13.

[12] Roullier, J. Z. \& Goldstein, I. L. (1993), 'The relationship between organizational transfer climate and positive transfer training', Human Resource Development Quarterly, 12(2): 105-120.

[13] Saks, A. M. (2002), 'So what is a good transfer of training estimate? a reply to Fitzpatrick', The Industrial-Organizational Psychologist, 39(3): 29-30.

[14] Saks, A. M. \& Belcourt, M. (2006), 'An investigation of training activities and transfer of training in organizations', Human Resource Management, 45(4): 629-648. 
[15] Saks, A. M. \& Burke, L. A. (2012), 'An investigation into the relationship between training evaluation and the transfer of training', International Journal of Training and Development, 16(2): 118-127.

[16] Sagafi-Nejad, T. (1991), 'International Technology Transfer Literature: Advances in Theory, Empirical Research, and
Policy', in Robinson, R. D. ed., The International Communication of Technology: A Book of Readings, Taylor and Francis, New York.

[17] Vitas_Executive Committee of Vietnam Textile and Apparel Association, Evaluation meeting of import and export situation of Vietnam's garment industry, 2013, 2014, and 2015. 